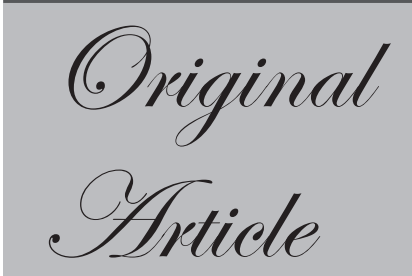

Department of Surgery, Government Medical College and Hospital, Sector 32 B, Chandigarh 160030, India

Corresponding Author: Dr Robin Kaushik Email:robinkaushik@yahoo.com

\section{Factors Influencing Morbidity and Mortality of Elective Stoma Closure}

\author{
Gaurav Shanker Pandey, Robin Kaushik, Simrandeep \\ Singh, Rajeev Sharma, Ashok Attri
}

ABSTRACT

Background: Stoma are often created in the emergency. These patients usually undergo restoration of bowel continuity electively 10 to 12 weeks later.

Material and Methods: Patients undergoing elective stoma closure were followed up for 3 months post-operatively for any morbidity (or mortality). Various patient and surgeon variables were analyzed to define factors that could affect the outcome of bowel restoration.

Results: Of the 80 patients included, 62 were male (77.5\%) and 18 (22.5\%) female with an average age of 37.8 years. The commonest indication of stoma creation was peritonitis $(52.5 \%)$; all patients underwent restoration after an average duration of 161.1 days. 47 patients (58.8\%) developed 62 morbidity events - commonly, wound infection (47.5\%), anastomotic leak $(15 \%)$ and early post-operative ileus $(6.25 \%)$. There were 4 deaths $(5 \%)$. Univariate analysis revealed significantly higher rate of anastomotic leakin patients with low BMI, low hemoglobin, low albumin, laparotomy for restoration, and American Society of Anesthesiology (ASA) grade III. -Post-operative obstruction was significantly associated with delay in closure, laparotomy, ASA grade III , and when consultants performed restoration. Mortality was significantly higher in patients with age above 55 years, low BMI, ASA grade III, low pre-operative hemoglobin and after anastomotic leak.

Conclusion: Restoration is not an innocuous procedure; significant morbidity and mortality is associated with it. Proper timing of closure as well as optimizing the patient help in reducing the morbidity and mortality of the operation.

KEYWORDS: Peritonitis, intestine, perforation, ostomy, reversal, anastomosis, anastomotic dehiscence, ileus, obstruction. 


\section{Introduction}

Creating a stoma is our favored approach when operating in the emergency, whether dealing with bowel perforation, obstruction or resection whenever a primary anastomosis is not considered safe. It is a quicker option that limits surgical stress in patients who are already compromised and avoids disastrous complications such as anastomotic leak that can 'push' such patients into an unsalvageable state. Making a stoma also confers the advantage of an early return to oral intake in the post-operative period. These 'temporary' stomas are closed electively after a period of ten to twelve weeks, and this operation of 'restoration' is considered to be relatively uncomplicated, with little, if any morbidity or mortality, since the acute phase of the primary disease (peritonitis, obstruction) and its sequelae are long over.

The aim of the present study was to evaluate our experience with stoma closure and to determine any factors that could predict the occurrence of morbidity and mortality in this group of patients.

\section{Material and Methods}

After Ethics Committee clearance, data was prospectively maintained for all patients undergoing stoma closure and willing to participate in the study. An optimal sample size for achieving statistical significance was determined to be 72 based on $10 \%$ absolute precision and $95 \%$ confidence interval. A total of 86 patients were enrolled over a period of six months, but only 80 patients completed the mandatory post-operative follow up of three months - the data of these 80 patients was analyzed. All patients were worked up in the outpatient department and admitted electively for bowel restoration. In addition to routine pre-operative work up, the distal bowel was assessed in 75 patients prior to operation.

Restoration was performed electively under general anesthesia - patients were operated by either a consultant or resident depending upon their availability during routine operative schedules and anticipated operative difficulty. Closure was done through the stoma site if the patient had both, proximal and distal limbs of the bowel at the same site; in case they were sited in different quadrants of the abdomen or there was a finding on distal loopogram that needed assessment, a formal laparotomy was performed. Anastomosis for restoration was performed as per surgeon's preference.

Post-operatively, the patients were returned to oral feeds based on assessment during daily rounds and discharged when fit. Patients who developed any complication after surgery were managed accordingly. Once discharged, the patients were followed up postoperatively at one week, one month, two months and finally, at three months.

The study was carried out in a prospective observational manner and statistical analysis of data was done at the end of the study using SPSS (version 22.0). Normality of quantitative data was checked by measures of Kolmogorov Smirnov tests; for normally distributed data, mean were compared using T-test; for skewed data or scores, Mann-Whitney U-test was used. For discrete categorical data, number and percentages were calculated and Chi-Square test or Fisher's Exact test were applied. All statistical tests were two sided. A p value of $<0.05$ was considered to indicate statistical significance.

\section{Results}

Of the total of 80 patients included in the study, there were 62 males $(77.5 \%)$ and 18 females $(22.5 \%)$. The mean age of all patients was 37.8 years (range $14-78$ years) and was slightly higher for males (mean age 45.3 years) than females (38.6years). The mean BMI was 18.4 $\mathrm{kg} / \mathrm{m}^{2}$ (range $11.4 \mathrm{~kg} / \mathrm{m} 2-32.8 \mathrm{~kg} / \mathrm{m}^{2}$ ), again, higher for males (mean $18.5 \mathrm{~kg} / \mathrm{m} 2)$ than females $\left(17.8 \mathrm{~kg} / \mathrm{m}^{2}\right)$. The commonest indication of stoma creation was peritonitis in $42(52.5 \%)$ followed by intestinal obstruction in 23 (28.8\%). The other indications were intra-abdominal malignancy (6), blunt abdominal trauma (6) and iatrogenic bowel perforation (3).

All patients were worked up through the OPD and scheduled for surgery after anesthetic clearance. 35 patients (43.8\%) had associated comorbidities such as tuberculosis, hypertension, malignancy, diabetes, HIV, $\mathrm{HCV}$ and mental retardation, but no patient was in ASA grade IV or V - the majority of patients belonged to ASA I (59) and ASA II (19). The distal bowel was assessed 
in 75 patients by distal loopogram (71), barium enema (03) or colonoscopy (01). These studies were normal in 73 patients, but revealed a colonic stricture in 1 patient, and an ileo-ileal fistula (from proximal to distal loop) in another.

Bowel restoration was done under general anesthesia in all patients - the majority of patients (61) underwent closure between 3 to 6 months; 18 were operated after 6 months, and one underwent surgery in less than three months after formation of stoma. The average duration of stoma prior to closure was 161.1 days (56 days - 484 days), and surgery for restoration was done through stoma site (locally) in $66(82.5 \%)$ patients, and via midline laparotomy in $14(17.5 \%)$. In the majority of cases, residents performed restoration (58 patients; $72.5 \%)$; in 22 (27.5\%), consultants operated. 55 (68.8\%) patients underwent ileo-ileal, 14 (17.5\%) underwent ileocolic and $11(13.8 \%)$ underwent colo-colic anastomosis - data on the suture material used and technique of anastomosis (interrupted or continuous, single or two layer) was not maintained. The demographics of the present series are tabulated in Table 1.

$47(58.8 \%)$ patients developed $62 \quad(77.5 \%)$ complications after restoration (Table 2). Wound infection was by far the commonest complication, seen in $38(47.5 \%)$ patients, followed by anastomotic leak in $12(15 \%)$. The majority of complications occurred during admission or within the first week after discharge

Table 1: Patient Data

\begin{tabular}{|c|c|c|c|}
\hline SI No. & & $\mathrm{n}=\mathbf{8 0}$ & Range \\
\hline 1. & MeanAge (years) & 37.83 & $14-78(\mathrm{SD} \pm 15.3)$ \\
\hline 2. & Male : Female ratio & $62: 18$ & \\
\hline 3. & MeanBMI & $18.38 \mathrm{~kg} / \mathrm{m}^{2}$ & $11.36-32.76 \mathrm{~kg} / \mathrm{m} 2(\mathrm{SD} \pm 4.34)$ \\
\hline 4. & Indication & $\begin{array}{l}\text { Perforation } 42(52.5 \%) \\
\text { Intestinal obstruction } 23(28.8 \%) \\
\text { Others } 15(18.75 \%)\end{array}$ & \\
\hline 5. & MeanStoma Duration (days) & 161.13 & $56-484(\mathrm{SD} \pm 82.27)$ \\
\hline 6. & Comorbidity & $35(43.75 \%)$ & \\
\hline 7. & ASA Grade & $\begin{array}{l}\text { ASA I } 59 \\
\text { ASA II } 19 \\
\text { ASA III } 2 \\
\end{array}$ & \\
\hline 8. & Mean Preoperative hemoglobin & $13.53 \mathrm{mg} / \mathrm{dl}$ & $8.7-16.6 \mathrm{mg} / \mathrm{dl}(\mathrm{SD} \pm 1.82)$ \\
\hline 9. & Mean Preoperative serum protein & $7.25 \mathrm{mg} / \mathrm{dl}$ & $4.6-10.4 \mathrm{mg} / \mathrm{dl}(\mathrm{SD} \pm 0.99)$ \\
\hline 10. & Mean Preoperative serum albumin & $3.99 \mathrm{mg} / \mathrm{dl}$ & $2.3-6.6 \mathrm{mg} / \mathrm{dl}(\mathrm{SD} \pm 0.68)$ \\
\hline 11. & Access during closure & $\begin{array}{l}\text { Stoma site } 66(82.5 \%) \\
\text { Laparotomy } 14(17.5 \%)\end{array}$ & - \\
\hline 12. & Operating Surgeon & $\begin{array}{l}\text { Resident } 58(72.5 \%) \\
\text { Consultant } 22(27.5 \%)\end{array}$ & - \\
\hline 13. & Type of anastomosis & $\begin{array}{l}\text { Ileo-ileal } 55(68.75 \%) \\
\text { Ileo-colic } 14(17.5 \%) \\
\text { Colo-colic } 11(13.75 \%)\end{array}$ & - \\
\hline 14. & Hospital stay (days) & 12 & $04-155(\mathrm{SD} \pm 22.11)$ \\
\hline 15. & Morbidity & $62(77.5 \%)$ events in 47 patients $(58.8 \%)$ & - \\
\hline 16. & Anastomotic leak & $12(15 \%)$ & - \\
\hline 17. & Reoperation & $07(8.75 \%)$ & - \\
\hline 18. & Readmission & $08(10 \%)$ & - \\
\hline 19. & Mortality & $04(05 \%)$ & - \\
\hline
\end{tabular}

SD (Standard Deviation) 
(44 patients), and only 3 patients presented with later complications. The overall duration of post-operative stay was 12 days (range 04 - 155 days), but was significantly higher when complications occurred (5.97 days versus 15.97 days). Of the 12 patients with anastomotic leak, 6 were re-operated; 5 had a low output enterocutaneous fistula that were successfully managed conservatively, and in 1 , the patient's son reported fecal discharge from the main wound after discharge from hospital and subsequent death before they could seek medical attention. There were $4(5 \%)$ deaths (including this patient) - all mortality in the present series occurred on a background of anastomotic leak.

When various factors were analyzed for morbidity and mortality (Table 3), it was seen that there was no particular factor that was significantly associated with wound infection. Anastomotic leaks were significantly higher in patients with a low hemoglobin, low albumin, those in whom laparotomy was performed for restoration and patients with ASA grade III risk assessment. Factors that were found to be significantly associated with postoperative intestinal obstruction were prolonged duration of stoma, laparotomy for restoration, ASA grade III patients, and those patients in whom the consultants performed restoration. Mortality was significantly higher in patients having age above 55 years, low BMI (less than $13.5 \mathrm{~kg} / \mathrm{m}^{2}$ ), ASA grade III, low pre-operative hemoglobin (less than $10.5 \mathrm{gm} / \mathrm{dl}$ ) and after the occurrence of anastomotic leak.

Table 2: Morbidity Events $(n=62)$

\begin{tabular}{l|l} 
Wound Infection & $38(47.5 \%)$ \\
\hline Anastomotic Leak & $12(15 \%)$ \\
\hline Intestinal Obstruction & $05(6.25 \%)$ \\
\hline Others (01 each of the following) & $07(8.75 \%)$ \\
- DVT & \\
- Incisional hernia & \\
- Herpes zoster infection & \\
- Midline skin necrosis (post laparotomy) & \\
- Ulnar nerve palsy (after venesection) \\
- Pneumothorax \\
- Unrelated perforation (sigmoid)
\end{tabular}

Table 3: Morbidity and Mortality $(n=80)$



* indicates significant values 


\section{Discussion}

The present series was a prospective observational study in which no attempt was made to modify existing surgical practices. Data on 80 patients undergoing elective restoration of bowel continuity for stoma formation in an emergency setting was maintained and these patients were followed up for three months following restoration to analyze outcomes and assess any variables that might be responsible for complications. All patients underwent elective restoration after a minimum waiting period of about 12 weeks from their primary surgery after being worked up through the OPD - workup included routine hematological and biochemical investigations in addition to assessmentof the distal bowel (normal in 73 of 75 patients). This probably indicates that routine distal bowel assessment should be done away with and should be performed selectively, such as in situations where there is a distal anastomosis or where disease pathology dictates (for example, in patients having tuberculosis with strictures documented at time of primary surgery). Even in the presence of distal anastomosis, there is controversy as to the necessity of distal bowel assessment ${ }^{1-4}$ - there are various reports that favor a selective approach, given the low yield, false-positive and false-negative rates of contrast enema as well as the potential for barium peritonitis. Keeping this in mind, as well as a few anecdotal experiences of retained barium in the distal loop causing obstruction after restoration, it seems be prudent to stick to a selective approach of distal bowel evaluation. ${ }^{5}$

\section{Timing of Closure}

Although early closure of stoma (as early as 8 days) has been documented to be safe $^{6}$ in an elective setting, most studies that deal with early closure are for stomas created for protecting an elective downstream anastomosis such as after resection of left sided colon cancers. ${ }^{7-10}$ There were no series that dealt with early closure of stomas created on a background of emergency surgery, and in such patients, it is the norm to wait for $2-3$ months from the primary surgery before performing restoration - this period of waiting has been proposed with the logic of allowing peritoneal inflammation to settle, the bowel to recover and become healthy enough to hold sutures, the primary disease to be controlled and the patient to come into a positive nutritional balance; it allows the period of hypervascularisation of adhesions to pass, edema on the stoma border to subside and the stoma to gain adequate vascularity; ${ }^{11-17}$ the flip side is dealing with stoma related complications and readmissions during this period. The majority of published literature still reports (and thereby indirectly supports) delayed closure of stomas that have been created the emergency. The optimum period seems to be within 3 to 6 months, ${ }^{18}$ and closing either before $^{12,19}$ or beyond ${ }^{11,18}$ this period has been reported to increase complications-early operations after sepsis are technically more demanding due to adhesions and inflammation whereas undue delay leads to the formation of dense adhesions and fixity of bowel loops.

\section{Morbidity of Restoration}

Restoration of bowel continuity is often considered a simple operation, with little complications. However, our experience shows a high morbidity $(77.5 \%)$, much higher than what has been previously documented (10.9 - 51.8\%). Wound infection (0.85 - 41.6\%), postoperative ileus / obstruction ( 0 - 32.6\%) and anastomotic leaks $(0-10 \%)$ are by far the commonest reported complications (Tables 2 and 4). ${ }^{12-31}$ In the present series, the majority of complications (95.7\%) occurred in hospital or within 30 days indicating that this is the most important period after restoration where one must be most vigilant; only 2 patients presented with complications (incisional hernia and unrelated, sigmoid perforation) after the first month following restoration. Although complications were analyzed separately and their risk factors evaluated individually, overall, low hemoglobin $(<10.5 \mathrm{gm} / \mathrm{dl})$ was the only factor found to be significant on multivariate analysis for the overall occurrence of morbidity events.

Individual analysis was performed for wound infections, anastomotic leaks and post-operative intestinal obstruction. Wound infection was by far our commonest complication (47.5\%) and possibly represents an overestimation of the problem since all patients having discharge from the surgical site were considered to have wound infection even in the absence of erythema, 
purulent nature of discharge or negative cultures. ${ }^{12}$ There was no variable in the present series that was significantly associated with the occurrence of wound infection. Various authors have reported that leaving the site open or closing it partially with a purse-string suture has a lower incidence of wound infection ${ }^{12,18}$ but unfortunately, this data was not maintained, and therefore we are unable to comment upon this aspect.

Leak is devastating after any anastomosis, and this was our second most common complication after restoration, seen in $12(15 \%)$ and is also higher than what is previously reported in Literature $(0-10 \%)$. This is possibly because most of the reported series deal with patients where stomas were created in an elective setting - only a few series ${ }^{13,14,19,29}$ were similar to ours (stomas created in emergency) and it has been previously reported that patients in whom primary surgery occurs in an emergency setting are more likely to have complications of stoma closure, ${ }^{21,33}$ leaks, high stoma output and necrosis ${ }^{34}$ and this might indirectly reflect a long recovery period from peritonitis ${ }^{33}$ or possibly, a continuation of inflammation (set into motion by the initial episode of peritonitis) at the subclinical / cellular level. It is well documented that apart from faulty technique, other factors that are known to increase the chances of leak include male sex, poor nutrition, obesity, steroid use, preoperative blood transfusions, prior irradiation and elderly age. ${ }^{18-21,27,33}$ We found that low hemoglobin (less than 10.5 $\mathrm{gm} / \mathrm{dl}$ ), low serum albumin (less than $2.9 \mathrm{gm} / \mathrm{dl}$ ), ASA grade III and laparotomy for closure were risk factors for anastomotic leak, which are surprisingly similar to those reported by Martinez (age above 50 years, ASA score equal or more than III, chronic renal failure, diffuse peritonitis, pre-operative hemoglobin less than $13 \mathrm{gm} / \mathrm{dl}$ and management with open abdomen). ${ }^{19}$ The average age of our patients was much lower than those of Martinez

Table 4: Recent literature on stoma closure.

\begin{tabular}{|c|c|c|c|c|c|c|c|}
\hline Author & Year & $\mathbf{n}$ & $\begin{array}{c}\text { Wound } \\
\text { infection } \\
n(\%)\end{array}$ & $\begin{array}{l}\text { Anastomotic } \\
\text { leak n (\%) }\end{array}$ & $\begin{array}{c}\text { Ileus / } \\
\text { Obstruction } \\
\text { n (\%) }\end{array}$ & $\begin{array}{c}\text { Overall } \\
\text { Morbidity (\%) }\end{array}$ & $\begin{array}{c}\text { Overall } \\
\text { mortality } \\
\text { n (\%) }\end{array}$ \\
\hline Chow $^{[20]}$ & 2009 & 6107 & $228(05)$ & $60(1.4)$ & $339(7.2)$ & 17.3 & 0.4 \\
\hline Martinez $^{[19]}$ & 2008 & 108 & NM & $11(10)$ & Not mentioned & Not mentioned & 06 \\
\hline $\mathrm{Saha}^{[21]}$ & 2008 & 327 & $24(7.0)$ & $13(4.0)$ & $32(10)$ & 22.8 & 2.5 \\
\hline Memon $^{[12]}$ & 2009 & 66 & $10(41.6)$ & $02(8.3)$ & 04 (16.6) & 36.36 & Not mentioned \\
\hline $\mathrm{Ali}^{[13]}$ & 2009 & 79 & $08(9.6)$ & $01(1.2)$ & $02(2.4)$ & 15.6 & nil \\
\hline Shelygin $^{[22]}$ & 2010 & 119 & $03(2.52)$ & Not mentioned & $09(7.56)$ & 10.92 & nil \\
\hline Akiyoshi ${ }^{[23]}$ & 2010 & 125 & $20(16)$ & Nil & $01(0.8)$ & 16.8 & nil \\
\hline Ballester $^{[14]}$ & 2012 & 89 & $04(4.5)$ & $01(1.12)$ & $29(32.6)$ & 45.9 & 1.12 \\
\hline Cipe $^{[15]}$ & 2012 & 255 & $11(4.3)$ & $05(1.9)$ & $16(6.3)$ & 18.4 & 1.2 \\
\hline Hussuna $^{[24]}$ & 2012 & 159 & $08(5.03)$ & $04(2.5)$ & $05(3.14)$ & 20.1 & nil \\
\hline Loffler ${ }^{[25]}$ & 2012 & 328 & $44(13.5)$ & $08(2.44)$ & $41(12.5)$ & NM & 0.4 \\
\hline $\operatorname{Tan}^{[25]}$ & 2012 & 49 & $03(6.1)$ & Nil & nil & 20.4 & nil \\
\hline Sharma ${ }^{[27]}$ & 2013 & 5401 & Not mentioned & Not mentioned & Not mentioned & 17.66 & 0.6 \\
\hline Marwaha $^{[28]}$ & 2013 & 100 & $20(20)$ & $01(1.0)$ & $01(1.0)$ & 36 & nil \\
\hline Afridi $^{[29]}$ & 2013 & 261 & $17(6.51)$ & $01(0.38)$ & $11(4.22)$ & 11.11 & nil \\
\hline Perez $^{[18]}$ & 2014 & 93 & $12(12.9)$ & $02(2.15)$ & $15(16.13)$ & 41 & 01 \\
\hline Poskus ${ }^{[30]}$ & 2014 & 132 & $04(03)$ & $04(03)$ & $09(6.8)$ & 18.2 & 1.5 \\
\hline Markides $^{[31]}$ & 2015 & 108 & $10(9.3)$ & $01(0.9)$ & $22(20.4)$ & 51.85 & 0.9 \\
\hline $\operatorname{Sier}^{[16]}$ & 2015 & 359 & Not mentioned & Not mentioned & Not mentioned & 31 & 0.9 \\
\hline Schneider $^{[32]}$ & 2016 & 118 & $01(0.85)$ & $02(1.69)$ & $01(0.85)$ & Not mentioned & Nil \\
\hline Present series & 2017 & 80 & $38(47.5)$ & $12(15)$ & $05(6.25)$ & 77.5 & 05 \\
\hline
\end{tabular}


19 (37.8 years versus 55 years) and this may be a reason why age was not significant for anastomotic leaks in our series. All our anastomotic leaks occurred within the first two weeks of restoration - of these, 05 were managed conservatively, 06 underwent re-operation and 01 died before any intervention could be performed. In the 06 patients who were re-operated, 04 underwent formation of stoma once again and 02 had a primary anastomosis after re-freshening.

Post-operative obstruction was the next common complication. In a major review of complications following ileostomy closure, Chow et $\mathrm{al}^{20}$ reported an overall incidence of $7.2 \%$ for obstruction across 48 studies and 6107 patients. Since then, various authors have reported obstruction after stoma closure up to $32.6 \%$ (Table 4). Unfortunately, many authors have not distinguished between ileus and bowel obstruction, often considering both together. ${ }^{20}$ In the present series, early obstruction was encountered in $05(6.25 \%)$ of patients and all of these patients with early obstruction responded to conservative management - possibly, labeling patients that respond to conservation as 'ileus' and those that need surgery as 'bowel obstruction' may be appropriate. ${ }^{29}$

Faulty technique, distal bowel obstruction, temporary edema at the site of closure, disparity of the lumen of the dysfunctional distal bowel, fixity of the bowel and a greater incidence of intra-abdominal adhesions after the primary operation have been attributed to bowel obstruction $^{11,12,15,18,35-37}$ after restoration; a few series ${ }^{11,18}$ have shown a higher incidence if restoration is delayed beyond six months, similar to our finding. In addition, other factors that were found to be significantly associated with higher incidence of ileus were - high ASA grade (III), low total serum protein (below $6 \mathrm{mg} / \mathrm{dl}$ ), laparotomy for access and surgery performed by a consultant (Table 3). Various authors have reported low hemoglobin ${ }^{21,32}$ obesity $^{32}$ male $^{18}$ or female ${ }^{24}$ sex, high ASA grades ${ }^{16,27}$ and low albumin ${ }^{21}$ as being responsible for higher morbidity of the procedure, but apart from resection prior to anastomosis ${ }^{24}$ and handsewn anastomosis (versus stapled) ${ }^{38}$ we could not come across any specific factors that influenced the occurrence of 'ileus' or 'intestinal obstruction' after restoration. When we analyzed serum proteins it was surprising to note that total serum protein less than $6 \mathrm{gm} / \mathrm{dl}$ (highly significant at a 'critical value' of less than $5.68 \mathrm{gm} / \mathrm{dl}$ ) was associated significantly with ileus, but low serum albumin was not. This may indirectly indicate that other, immune related factors might also be responsible for the development of ileus / obstruction after restoration. Ileus occurred more commonly in patients who underwent laparotomy and in those in whom surgery performed by a consultant - this probably represents a selection bias ${ }^{24}$ where anticipated difficult / complex cases were operated primarily by the consultant.

\section{Mortality}

There were 4 deaths, all occurring in patients who developed anastomotic leak. Variables that were associated with mortality were age (above 55 years), low BMI (less than $13.5 \mathrm{~kg} / \mathrm{m}^{2}$ ), ASA grade III, low pre-operative hemoglobin (less than $10.5 \mathrm{gm} / \mathrm{dl}$ ) and anastomotic leak. This combination of advanced age, compromised functional and nutritional status should be factored in prior to closure and such need to be patients carefully monitored. ${ }^{29}$ Albumin less than $3.4^{21}$ and high ASA grade ${ }^{16}$ have been reported previously to be significantly related to the mortality of the procedure in addition to stoma reversal within first three months. ${ }^{19}$ Though we also noted a higher mortality in patients who were operated earlier, (average 106.5 days versus 161.13 days in survivors), this was not a significant factor towards mortality, probably because this three months (early) period had been crossed.

\section{Study Limitations}

This series is probably one of the first from the region to highlight various risk factors for outcomes after bowel restoration, but it has its limitations. The first one being that the study population was not heterogeneous, especially in terms of the primary disease (broadly from emergency surgery, but including patients with peritonitis, malignancy, obstruction) and the type of stoma being closed. Our patients had ileostomy as well as colostomy and the closures included ileo-ileal, ileo-colic as well as colo-colic anastomosis. Although we found no statistical difference between either group in terms of primary 
disease as well as site of stoma and type of anastomosis, further studies might do well to include only one type of disease or stoma to reduce the potential for statistical bias. Another limitation was that data on the type of anastomosis performed was not maintained - due to financial constraints, we prefer hand sewn anastomosis, but data on the type of suture used and technique of closure (single versus two layers, interrupted versus continuous) as well as the nature and number of complications in patients undergoing stoma closure without resection with just freshening of margins and repair versus those undergoing a resection anastomoses was missing. The third limitation was that data on wound closure was not recorded, thereby not allowing us to evaluate wound infections versus open or closed wounds.

\section{Conclusion}

Despite its limitations, the present series highlights a high rate of complications that are associated with stoma closure on a background of emergency surgery - even when performed electively after an 'adequate' interval; there is a high morbidity (77.5\%) and mortality (5\%). Wound infection, anastomotic leak and post-operative ileus are common, and the majority of complications occur within the first week following restoration; mortality usually occurs on a background of anastomotic leak.

Optimizing patients nutritionally as well as operating at an appropriate time interval might help in reducing the morbidity and mortality of the procedure. The lacunae in the present series might help future researchers in planning a more comprehensive study to evaluate outcomes after stoma closure.

\section{References}

1. Cowan T, Hill AG. IleostomyClosure Without Contrast Study Is Safe In Selected Patients. ANZ J Surg 2005; 75: $218-19$

2. Hong SY, Kim DY, Oh SY, Suh KW. Routine barium enema prior to closure of defunctioning ileostomy is not necessary. J Korean SurgSoc2012; 83: 88 - 91.

3. Dimitriou N, Panteleimonitis S, Dhillon A, Boyle K, Norwood M, Hemingway D, et al. Is the routine use of a water-soluble contrast enema prior to closure of a loop ileostomy necessary? A review of a single institution experience. World JSurgOncol 2015; 13: 331.

4. Girish KK, Vishwas DP, Supreeta A, Prachi P, Avanish PS. Role of Distal loopogram Before Defunctioning Stoma Reversal - Results From An Indian Tertiary-Care Center. Canc Therapy \&OncolIntJ 2016; 1: 555574.

5. Saini P, Gupta P, Sharma A, Agarwal N, Kaur N, Gupta A. Should routine contrast study be a norm before stoma reversal? A retrospective study of patients with temporary ileostomy. Tropical Doctor 2013; 43: 57 - 61

6. Alves A, Panis Y, Lelong B, Dousset B, Benoist S, Vicaut E. Randomized clinical trial of early versus delayed temporary stoma closure after proctectomy. Br J Surg 2008; 95: 693 - 8.

7. Zhou MW, Wang ZH, Chen ZY, Xiang JB, Gu XD. Advantages of Early Preventive Ileostomy Closure after Total Mesorectal Excision Surgery for Rectal Cancer: An Institutional Retrospective Study of 123 Consecutive Patients. Dig Surg2016 (Epub ahead of print).

8. Danielsen AK, Park J, Jansen JE, Bock D, Skullman S, Wedin A et al. Early Closure of a Temporary Ileostomy in Patients With Rectal Cancer: A Multicenter Randomized Controlled Trial. Ann Surg 2017; 265: 284 - 90.

9. Lasithiotakis K, Aghahoseini A, Alexander D. Is Early Reversal of Defunctioning Ileostomy a Shorter, Easier and Less Expensive Operation? World J Surg 2016; 40: 1737 40.

10. Robertson JP, Puckett J, Vather R, Jaung R, Bissett I. Early closure of temporary loop ileostomies: a systematic review. Ostomy Wound Manage 2015; 61: 50 - 7.

11. Perez RO, Habr-Gama A, Seid VE, Proscurshim I, Sousa AH, Kiss DR, et al. Loop ileostomy morbidity: timing of closure matters. Dis Colon Rectum. 2006; 49: 1539 - 45.

12. Kaider-Person O, Person B, Wexner SD. Complications of Construction and Closure of Temporary Loop Ileostomy. J Am CollSurg2005; 201: 759 - 73.

13. Memon ZA, Qureshi S, Murtaza M, Maher M. Outcome of Ileostomy Closure: An Audit in Surgical Ward 2, JPMC, Karachi. Pak J Surg 2009; 25: 230 - 4.

14. Ali SA, Soomro AG, Memon SM, Shaikh NA. Postoperative Complications of Reversal of Loop Ileostomy. JLUMHS 2009; 8: $23-5$.

15. Mengual-Ballester M, García-Marín JA, Pellicer-Franco E, Guillén-Paredes MP, García-García ML, Cases-Baldó MJ, et al. Protective ileostomy: complications and mortality associated with its closure. Rev EspEnferm Dig (Madrid) 2012; 104: 350 - 4 .

16. Cipe G, Erkek B, Kuzu A, Gecim E (2012). Morbidity and 
Mortality after the Closure of a Protective Loop Ileostomy: Analysis of Possible Predictors. Hepato-Gastroenterology 2012; 59: $2168-72$.

17. Sier MF, van Gelder L, Ubbink DT, Bemelman WA, Oostenbroek RJ. Factors affecting timing of closure and non-reversal of temporary ileostomies. Int J Colorectal Dis 30: 1185 - 92.

18. Rubio-Perez I, Leon M, Pastor D, Diaz Dominguez J, Cantero R. Increased postoperative complications after protective ileostomy closure delay: An institutional study. World J GastrointestSurg2014; 6: 169 - 174.

19. Martínez JL, Luque-de-León E, Andrade P. Factors related to anastomotic dehiscence and mortality after terminal stomal closure in the management of patients with severe secondary peritonitis. J GastrointestSurg 2008; 12: 2110 8.

20. Chow A, Tilney HS, Paraskeva P, Jeyarajah S, Zacharakis E, Purkayastha S. The morbidity surrounding reversal of defunctioning ileostomies: a systematic review of 48 studies including 6,107 cases. Int J Colorectal Dis 2009; 24: 711 - 23.

21. Saha AK, Tapping CR, Foley GT, Baker RP, Sagar PM, Burke DA, et al. Morbidity and mortality after closure of loop ileostomy. Colorectal Dis 2009; 11: 866 - 71.

22. Shelygin YA, Chernyshov SV, Rybakov EG. Stapled ileostomy closure results in reduction of postoperative morbidity. Tech Coloproctol2010; 14: 19 - 23.

23. Akiyoshi T, Fujimoto Y, Konishi T, Kuroyanagi H, Ueno M, Oya M, et al. Complications of loop ileostomy closure in patients with rectal tumor. World J Surg 2010; 34: 1937 $-42$.

24. El-Hussuna A, Lauritsen M, Bülow S. Relatively high incidence of complications after loop ileostomy reversal. Dan Med J 2012; 59: A4517

25. Löffler T, Rossion I, Bruckner T, Diener MK, Koch M, von Frankenberg M, et al; HASTA Trial Group. HAnd Suture Versus STApling for Closure of Loop Ileostomy (HASTA Trial): results of a multicenter randomized trial (DRKS00000040). Ann Surg 2012; 256: 828 - 35; discussion 835-6.

26. Tan WS, Lim JF, Tang CL, Eu KW. Reversal of Hartmann's procedure: experience in an Asian population. Singapore Med J 2012; 53: 46 - 51.

27. Sharma A, Deeb AP, Rickles AS, Iannuzzi JC, Monson
JRT, Fleming FJ. Closure of defunctioning loop ileostomy is associated with considerable morbidity. Colorectal Dis2013; 15: $458-62$.

28. Marwah S, Singla S, Tinna P. Role of gum chewing on the duration of postoperative ileus following ileostomy closure done for typhoid ileal perforation: A prospective randomized trial. Saudi J Gastroenterol 2012; 18: 111 - 7.

29. Afridi SS, Ahmed N, Zarin M, Muslim M, Aurangzeb M. Outcome of loop ileostomy reversal: A prospective study. Khyber Med Univ J 2013; 5: 128 - 31.

30. Poskus E, Kildusisa E, Smolskas E, Ambrazevicius M, Strupas K. Complications after Loop Ileostomy Closure: A Retrospective Analysis of 132 Patients. Viszeralmedizin 2014; 30: $276-80$.

31. Markides GA, WijetungaI, McMahon M, Gupta P, Subramanian A, Anwar S. Reversal of loop ileostomy under an Enhanced Recovery Programme - Is the stapled anastomosis technique still better than the handsewn technique? Int J Surg2015; 23: $41-45$.

32. Schneider V, Lee LD, Stroux A, Buhr HJ, Ritz JP, Kreis $\mathrm{ME}$, et al. Risk factors for reoperation after ileostomy reversal - Results from a prospective cohort study. Int $\mathrm{J}$ Surg2016; 36: 233 - 9.

33. Pearce NW, Scott SD, Karran SJ. Timing and method of reversal of Hartmann's procedure. Br J Surg 1992; 79: 839 $-41$.

34. Leenen LPH, Kuypers JHC. Some Factors Influencing the Outcome of Stoma Surgery. Dis Colon Rect1989; 32: 500 -4 .

35. van de Pavoordt HD, Fazio VW, Jagelman DG, Lavery IC, Weakley FL. The outcome of loop ileostomy closure in 293 cases. Int J Colorectal Dis 1987; 2: 214 - 7.

36. Mann LJ, Stewart PJ, Goodwin RJ, Chapuis PH, Bokey EL. Complications following closure of loop ileostomy. Aust N Z J Surg 1991; 61: 493 - 6.

37. Law WL, Chu KW, Choi HK. Randomized Clinical Trial Comparing Loop Ileostomy and Loop Transverse Colostomy for Faecal Diversion following Total Mesorectal Excision. Br J Surg 2002; 89: $704-8$.

38. Löffler T, Rossion I, Gooßen K, Saure D, Weitz J, Ulrich A, et al. Hand suture versus stapler for closure of loop ileostomy - a systematic review and meta-analysis of randomized controlled trials. Langenbecks Arch Surg 2015; 400: 193 - 205. 